Original Article

\title{
Effect of breathing maneuver combined with upper extremity exercise on respiratory capacity in healthy adult men
}

\author{
Ji Won Han, MSc, PT ${ }^{1)^{*}}$, Kyoung Kim, PhD, PT ${ }^{1)}$, Seong Hoon Park, MSc, $\mathrm{PT}^{1)}$, \\ Doo Ho LeE, MSc, $\mathrm{PT}^{1)}$ \\ 1) Department of Physical Therapy, College of Rehabilitation Science, Daegu University: \\ 201 Daegudae-ro, Gyeongsan-si, Gyeongsangbuk-do 712-714, Republic of Korea
}

\begin{abstract}
Purpose] This study aimed to determine the effect of the breathing maneuver combined with dynamic motion of the upper limbs on respiratory capacity in healthy adult men. [Subjects and Methods] Twenty-four healthy adult men participated in this study. Subjects were randomly assigned to a control group $(n=12)$ or an experimental group $(\mathrm{n}=12)$. The subjects in the control group performed the breathing maneuver without the upper extremity exercise. The subjects in the experimental group performed upper extremity exercise with the breathing maneuver three times a week for 4 weeks. Outcomes were measured using maximum inspiratory and expiratory pressures. [Results] There was a significant difference in maximum inspiratory and expiratory pressures before and after intervention in the experimental group and the control group. In addition, there was a significant difference in maximal expiratory pressure between groups after intervention. [Conclusion] The results of this study suggest the respiration maneuver combined with upper extremity exercise could be used as a program for clinical respiration training.

Key words: Breathing maneuver, Respiratory capacity
\end{abstract}

(This article was submitted Jan. 17, 2017, and was accepted Mar. 11, 2017)

\section{INTRODUCTION}

Functional activities of the human body are related to the co-contractions of deep and superficial trunk muscles ${ }^{1)}$. However, deep abdominal muscles of the trunk contribute to active breathing as well as to stability ${ }^{2}$. The transverses abdominis of the abdominal muscles work together as diaphragm partners, and the contractions of these muscles act on strong expiration. At the maximal expiration, the activity changes of the transversus abdominis are greater than the other abdominal muscles $^{3}$. Forced expiration is produced by contractions of the transversus abdominis, external oblique abdominal muscle, internal oblique abdominal muscle, and rectus abdominis ${ }^{4}$. The maximum expiratory maneuver can promote the activity of the transversus abdominis surrounding the abdomen through contraction of the diaphragm ${ }^{5}$, and this breathing training can help strengthen contraction of the transversus abdominis and thereby, improve lung exhalatory function ${ }^{6}$. Inspiration refers to the inflow of air due to contraction and descent of the diaphragm, and increases intra-abdominal pressure and lowers intrathoracic pressure. The transversus abdominis is located in the innermost layer among abdominal muscles, and is responsible for compressing and sustaining internal abdominal organs and contributes to increasing intra-abdominal pressure $^{3)}$. When intrathoracic pressure is lowered due to contractions of the external intercostalis, sternocleidomastoid, scalenus, and trapezius, powerful inspiration becomes possible ${ }^{7}$. The inspiratory muscles that elevate the ribs include the pectoralis major, pectoralis minor, serratus anterior, which originates at the shoulder girdle and the humerus, the levatores costarum, the serratus posterior superioris, which originates at the backbone, and the sternocleidomastoid and scalenus, which originate

*Corresponding author. Ji Won Han (E-mail: damgeom@naver.com)

(C2017 The Society of Physical Therapy Science. Published by IPEC Inc.

This is an open-access article distributed under the terms of the Creative Commons Attribution Non-Commercial No Derivatives (by-nc-nd) License $<$ https://creativecommons.org/licenses/by-nc-nd/4.0/>. 
at the head and neck. These muscles expand the thoracic cage further and make inhalation possible ${ }^{4)}$. As described above, studies on respiration and research on the effects of breathing maneuvers on the activity and thickness of abdominal muscles are being actively conducted. However, little information is available on the combined effects of breathing maneuvers and upper extremity exercise on respiratory capacity. Therefore, in the present study, we undertook to investigate the combined effects of a breathing maneuver and dynamic motion of upper limbs on respiratory capacity as compared with a breathing maneuver alone.

\section{SUBJECTS AND METHODS}

Twenty-four healthy adult men participated in this study. The inclusion criteria applied were; no diagnosis of a pathological problem in the respiratory system, and no regular cardiopulmonary exercise within six months of study commencement. All participants meeting the inclusion criteria were given verbal and written information on the purpose of this study and provided written informed consent. In addition, the human rights of subjects were protected. The 24 study subjects were randomly assigned to an experimental group $(n=12)$ or a control group $(n=12)$. The participants in the control group were allowed to perform the breathing maneuver without upper extremity exercise, whereas participants in the experimental group performed the upper extremity exercise using $3 \mathrm{~kg}$ dumbbells, which involved 50 minutes exercise consisting of shoulder joint abduction, flexion, and horizontal adduction, while sitting on a chair. Breathing exercise was performed using the controlled breathing method at the same time as the upper extremity exercise, and consisted of breathing in fully through the nose for 3 seconds and then breathing out through the mouth for 6 seconds with a 20 -second break between breaths ${ }^{8)}$. Members of the experimental group performed the combined breathing/upper extremity exercise three times a week for 4 weeks, whereas members of the control group performed the breathing exercise.

Respiratory capacity was determined by measuring maximum inspiratory pressure (MIP) and maximum expiratory pressure (MEP) using the Micro Respiratory Pressure Meter. Collected data were analyzed using SPSS ver. 18.0. The paired $\mathrm{t}$-test was used to determine the significances of differences after intervention, and the independent samples t-test was used to determine the significances of intergroup differences. Statistical significance was accepted for $\mathrm{p}$ values $<0.05$.

\section{RESULTS}

Demographic characteristics were similar in the experimental and control groups (Table 1). After exercise, there were significant differences in maximum inspiratory and expiratory pressures in both groups $(\mathrm{p}<0.05)$ (Table 2). There were no significant intergroup differences in maximum inspiratory pressure. However, significant intergroup differences were observed between maximum expiratory pressure after exercise $(\mathrm{p}<0.05)$ (Table 3$)$.

\section{DISCUSSION}

The purpose of this study was to determine the effect of a breathing maneuver combined with upper extremity exercise on the respiratory capacities of healthy adult men versus that achieve using the single breathing exercise. The study shows that combined breathing/upper extremity exercise increases maximum expiratory pressure more than breathing exercise alone.

This is thought to be due to the fact that abdominal muscles, which play a major role in active exhalation, were activated and intra-abdominal pressure was increased by the diaphragm working with the transversus abdominis during the combined dynamic upper extremity/expiratory breathing exercise. By performing dynamic upper limb movements during breathing expiration, abdominal muscle activation, which plays a major role in active aerobic exercise, and increased diaphragmatic pressure by diaphragm acting in conjunction with the abdominal muscles ${ }^{9}$. The contractions of the upper muscles of the intercostal muscles and sternocleidomastoid muscles, the scalene muscles, and upper trapezius muscles further reduce the intrathoracic pressure and enable intense inspiration ${ }^{7}$. When upper extremity movement begins, diaphragm increases abdominal pressure and allows strong exhalation ${ }^{10)}$. Tarnanen et al. found that dynamic upper extremity exercise was useful for activating abdominal muscles ${ }^{11)}$, and Park reported that the abdominal expiratory strategy significantly increased transversus abdominis thickness ${ }^{12)}$. Goo et al. also reported that the thickness of the transversus abdominis was significantly increased on the sonographs when the maximal expiratory maneuver was applied to healthy people ${ }^{6}$. In addition, Ishida et al. reported that the activation of deep abdominal muscles was promoted by the maximal expiratory maneuver ${ }^{13)}$. It was also reported that there was a significant increase in the thickness of the internal obliques and transverse abdominal muscles compared to the single abdominal drawing-in technique in the abdominal drawing-in technique with upper extremity exercise ${ }^{14)}$. These previous results are believed to provide a basis for understanding the results of this study, which suggests the observed positive effect of combined upper extremity/expiratory exercise on respiratory capacity could be used to design a program for clinical respiration training.

The limitations of this study are that upper extremity exercise movements were limited and that the study was relatively short. In addition, as the study was conducted on healthy adult men in their twenties it is difficult to generalize our results. Additional studies are required to determine how respiratory capacity is changed by different upper extremity exercises in the 
Table 1. General characteristics of the subjects

\begin{tabular}{lcc}
\hline & $\begin{array}{c}\text { Experimental group } \\
(\mathrm{n}=12)\end{array}$ & $\begin{array}{c}\text { Control group } \\
(\mathrm{n}=12)\end{array}$ \\
\hline Age (years) & $23.6 \pm 1.3$ & $27.7 \pm 1.2$ \\
Weight $(\mathrm{kg})$ & $75.2 \pm 0.9$ & $71.0 \pm 0.9$ \\
Height $(\mathrm{cm})$ & $176.5 \pm 3.7$ & $173.6 \pm 6.1$ \\
Right grip strength $(\mathrm{N})$ & $43.9 \pm 9.6$ & $44.6 \pm 8.6$ \\
Left grip strength $(\mathrm{N})$ & $42.4 \pm 8.8$ & $42.8 \pm 7.0$ \\
\hline
\end{tabular}

Values are means \pm standard deviation.
Table 3. Between-group comparison

\begin{tabular}{lcc}
\hline & $\begin{array}{c}\text { Experimental group } \\
(\mathrm{n}=12)\end{array}$ & $\begin{array}{c}\text { Control group } \\
(\mathrm{n}=12)\end{array}$ \\
\hline $\mathrm{MEP}\left(\mathrm{cmH}_{2} \mathrm{O}\right)$ & $140.5 \pm 4.9$ & $122.5 \pm 5.4^{*}$ \\
$\mathrm{MIP}\left(\mathrm{cmH}_{2} \mathrm{O}\right)$ & $126.0 \pm 4.5$ & $115.9 \pm 4.9$ \\
\hline \multicolumn{3}{l}{ Values are means \pm standard deviation. } \\
*P significant between groups after training $(\mathrm{p}<0.05)$ \\
\multicolumn{2}{l}{$\begin{array}{l}\text { MEP: maximum expiratory pressure; MIP: maximum inspi- } \\
\text { ratory pressure }\end{array}$}
\end{tabular}

Table 2. Outcome measures

\begin{tabular}{lcccc}
\hline & \multicolumn{2}{c}{ Experimental group $(\mathrm{n}=12)$} & \multicolumn{2}{c}{ Control group $(\mathrm{n}=12)$} \\
\cline { 2 - 5 } & Pre-training & Post-training & Pre-training & Post-training \\
\hline $\mathrm{MEP}\left(\mathrm{cmH}_{2} \mathrm{O}\right)$ & $88.3 \pm 27.8$ & $131.4 \pm 26.4^{*}$ & $114.2 \pm 16.9$ & $133.2 \pm 21.4^{*}$ \\
$\mathrm{MIP}\left(\mathrm{cmH}_{2} \mathrm{O}\right)$ & $97.2 \pm 27.0$ & $122.0 \pm 28.4^{*}$ & $107.8 \pm 25.7$ & $120.6 \pm 24.1^{*}$ \\
\hline
\end{tabular}

Values are means \pm standard deviation.

*P significant vs. post-training $(\mathrm{p}<0.05)$

MEP: maximum expiratory pressure; MIP: maximum inspiratory pressure

long term and to determine the effects of upper extremity exercise combined with different breathing techniques on patients with respiratory diseases.

\section{REFERENCES}

1) McGill SM, Grenier S, Kavcic N, et al.: Coordination of muscle activity to assure stability of the lumbar spine. J Electromyogr Kinesiol, 2003, 13: 353-359. [Medline] [CrossRef]

2) Henke KG, Sharratt M, Pegelow D, et al.: Regulation of end-expiratory lung volume during exercise. J Appl Physiol 1985, 1988, 64: 135-146. [Medline]

3) Richardson CA, Snijders CJ, Hides JA, et al.: The relation between the transversus abdominis muscles, sacroiliac joint mechanics, and low back pain. Spine, 2002, 27: 399-405. [Medline] [CrossRef]

4) Lee JY, Jung JH, Jung EJ, et al.: The effect of feedback breathing exercise and treadmill exercise on chest length and pulmonary function of the middle-aged. J Spec Educ Rehabil Sci, 2013, 52: 319-333.

5) Blandine CG: Anatomy of breathing. Seattle: Eastland Press, 2006.

6) Goo BO, Kim KH: A comparison of lateral abdominal muscle activation during maximum expiration in chronic low back pain patients and healthy asymptomatic subjects. J Korea Proprioceptive Neuromuscul Facilitation Assoc, 2014, 12: 39-43.

7) Lee GW, Yoon TI, Kim KS, et al.: Electromyographic activity of abdominal muscles during lumbopelvic stabilization exercises. J Phys Ther Kor, 2014 , 21: 1-7. [CrossRef]

8) Jones AY, Dean E, Chow CC: Comparison of the oxygen cost of breathing exercises and spontaneous breathing in patients with stable chronic obstructive pulmonary disease. Phys Ther, 2003, 83: 424-431. [Medline]

9) Khedr EM, El Shinawy O, Khedr T, et al.: Assessment of corticodiaphragmatic pathway and pulmonary function in acute ischemic stroke patients. Eur J Neurol, 2000, 7: 509-516. [Medline] [CrossRef]

10) Hodges PW, Richardson CA: Transversus abdominis and the superficial abdominal muscles are controlled independently in a postural task. Neurosci Lett, 1999, 265: 91-94. [Medline] [CrossRef]

11) Tarnanen SP, Siekkinen KM, Häkkinen AH, et al.: Core muscle activation during dynamic upper limb exercises in women. J Strength Cond Res, 2012, 26: 3217-3224. [Medline] [CrossRef]

12) Park DJ: Altered respiratory pattern of individuals with low back pain and effects of abdominal exhalation maneuver. Busan: Catholic University, 2013.

13) Ishida $\mathrm{H}$, Hirose $\mathrm{R}$, Watanabe $\mathrm{S}$ : Comparison of changes in the contraction of the lateral abdominal muscles between the abdominal drawing-in maneuver and breathe held at the maximum expiratory level. Man Ther, 2012, 17: 427-431. [Medline] [CrossRef]

14) Park SK, Kim YN, Jung EY, et al.: The effects of abdominal drawing-in maneuver with shoulder isometric contractions on abdominal muscles thickness in healthy person. J Phys Ther Kor, 2013, 20: 38-45. [CrossRef] 